\title{
REFLEXÕES SOBRE OS CONCEITOS DO RESTAURAR E RECONSTITUIR
}

José Luiz Mota Menezes*

* Arquiteto e ex-presidente do
Institutoráricológico,
Histórico e Geográfico de
RESUMO: Em se considerando os diversos procedimentos de restauração de bens móveis e imóveis, o artigo disserta sobre o restaurar e a reconstituição, às vezes necessárias, de bens materiais destruídos ou com intervenções nas quais deles foram retiradas as razões do existir, isto por causas de guerras ou remodelações ruins. Trata dos bens culturais da pintura e da escultura e os difere daqueles que são edificados, bens materiais, que possuem uma data de início e nem sempre são concluídos ou estão sujeitos a mudanças segundo os gostos das gerações que convivem com os mesmos.

Palavras-chave: Restauração; Reconstituição; Bem Material; Intervenção; Arquitetura.

ABSTRACT: Considering the various procedures for the restoration of movable and immovable property, the article discusses the restoration and reconstitution of material goods destroyed or with interventions in which the reasons for their existence were removed, due to the causes of wars or bad remodels. It treats the cultural goods of painting and sculpture and differ them from those that are built, material goods, which have a start date and are not always completed or are subject to changes according to the tastes of the generations that live with them.

Keywords: Restoration; Reconstitution; Material Well; Intervention; Architecture. 
Em Roma foi destruído parte do rosto da escultura de Miguel Ângelo, a Piedade, exposta em uma das capelas da Basílica de São Pedro. $O$ dano atingiu o nariz e pequena parte do restante do rosto da Virgem. Um especialista, então brasileiro, restaurou o dano. Hoje a escultura encontra-se restituída em sua extraordinária beleza. 0 emprego do verbo restaurar parece perfeito e significando o ato ou efeito de restaurar dos dicionaristas ${ }^{1}$.

No Instituto Arqueológico, Histórico e Geográfico Pernambucano, uma tela encontrava-se com pequenos danos e rasgada em parte. A restauração reparou o dano na pintura, segundo técnica conhecida e empregada pelo profissional responsável e o rasgo foi também devidamente reparado. Nada havia desaparecido na tela. Estava ela apenas danificada, devido ao tempo de vida e outras pequenas causas. A ação restaurar está em acordo com a definição dos dicionaristas.

Outra tela faltava um pedaço do rosto. Então houve de reparar o dano, então reconstituindo o trecho que faltava mediante o conhecimento, por fotografia, da parte que faltava. A restauração reconstituiu o pedaço que faltava. $O$ trecho que faltava não pode ser considerado de mesmo tempo do restante da tela, uma vez que a reconstituição pode ser uma conjectura. Mesmo com fotografias do trecho desaparecido, falta a pátina do tempo².

Em uma igreja, um bem material imóvel, uma boa parte do arco cruzeiro, em alvenaria de pedra, ruiu e sua restauração aconteceu mediante o uso de cantaria seguindo os detalhes da parte que existia. Noutra igreja, o arco ruiu e as pedras foram roubadas nada restando dessa parte da edificação. Existiam fotografias do arco e desenhos em escala do mesmo. Então não aconteceu uma restauração e sim uma reconstituição do elemento que faltava na leitura do ambiente. Neste caso, o emprego do verbo restaurar não parece correto.

Uma igreja sofreu uma intervenção indesejável e a proposta seria restaurar o monumento. Do edifício anterior restavam elementos que ainda não estavam danificados e outros encobertos por ornatos de tempos diferentes. Seria correto o emprego do verbo restaurar nesse caso? Como se encontrava, o edifício nada representava senão uma sucessão de situações que amesquinhavam sua importância ${ }^{3}$, uma vez que as intervenções o danificaram, esteticamente, de maneira a torna-lo irreconhecível. Seria lógico o deixar com estava? Aplicaríamos, nesse caso, os conceitos de J. Ruskin, onde o certo seria a manutenção dos diversos elementos que foram danificando seu aspecto ${ }^{4}$ Em sendo sim a resposta, nada deveria ser realizado e o bem

\footnotetext{
${ }^{1}$ Sobre a restauração da pintura e da escultura, assim também de outros bens diferentes da arquitetura existe toda uma série de ações estruturada e várias publicações, além de estudos de casos das oficinas de restauração.

${ }^{2}$ Restaurar é a palavra e uso geral, empregada em todas as ações que envolvam a reparação do bem danificado. No entanto a reconstituição é outra palavra que tem como diferença é a completude do objeto danificado de partes desaparecidas por danos identificados por perda ou destruição, quais aquelas decorrentes de conflitos, por exemplo, como as guerras. $\mathrm{O}$ reconstituir deveria ser fundamentado em documentação segura e aceita pela história do bem cultural.

${ }^{3}$ A avaliação dos danos e sua relação com o bem cultura, diante da comunidade que o utiliza, é um aspectos de grande importância no que se refere as decisões sobre restaurar o referido bem cultural. Um bem cultural não resultado somente de alguns, assim parece, mas deve atender a sociedade como um todo. Mesmo que a iniciativa tenha sido de poucos, ela deve estar direcionada para todos em suas aspirações culturais. Nem sempre as decisões tem tal condição como prioritária, isto quer na escolha ou na decisão do restaurar.

${ }^{4} \mathrm{O}$ escritor e crítico de arte J. Ruskin poderia ser considerado também um dos resultados de uma visão da arte no Romantismo. Existem razões para a sua defesa da permanência da condição tempo e mudanças no corpo da edificação. Naturalmente, esta é condição natural e inerente à arquitetura enquanto utilitária e transformada pelas gerações. No entanto, deixar um estado de
} 
seria deixado irreconhecível para a comunidade, portanto talvez longe de sua importância, enquanto representativo da sociedade que o edificou. Seria o caso, por exemplo, de uma igreja qual a Notre Dame, em Paris, onde os revolucionários franceses destruíram sensivelmente as esculturas e demais elementos da contrafação principal. Deixar assim seria certo? Ou ainda, os bens danificados quando da 2 a Guerra Mundial. Seria certo deixar testemunhos de um dano que somente amesquinha o valor do monumento? Parece-nos que, sendo possível reparar, o verbo empregado seria reconstituir o destruído, desde que devidamente documentado o que desapareceu ${ }^{5}$.

No Recife, a Igreja do Convento do Convento dos Franciscanos, na Rua do Imperador, sofreu no século XIX uma intervenção no corpo da nave, onde partes da decoração do século XVII foram recobertas por elementos ornamentos ecléticos daquele século. Na capela-mor um forro abobadado, de madeira, entalhado com ornatos, no século XIX, foi instalado abaixo de uma abóbada de alvenaria de tijolos, da primeira metade do século XVII, revestida internamente de azulejos seiscentistas. Tal abóbada, em madeira, teve por objetivo tornar essa capela condizente com a reforma daquela nave. No corpo da nave, no coro, em sua parte inferior mantiveram-se pinturas, em caixotões, datáveis do século XVIII. Diante da importância e estado de conservação daquela abóbada em alvenaria, o ato dito de restauração conduziu para a remoção da abóbada em madeira, com o objetivo de expor aquela abóbada azulejada e remover para outro espaço do convento, a abóbada de madeira. Neste caso, não aconteceu uma restauração, mas aplicou-se um conceito que não tem, quanto a leitura do todo dos dois ambientes, respaldo em tempo algum, uma vez que deriva do interesse de valorizar tempos diferentes, não pertencentes a nenhum específico, contrariando o princípio de completude e unidade, identificado nos exemplos antes relacionados das pinturas e na escultura. $O$ considerado no resultado foi uma possível Harmonia entre os tempos e gostos estéticos de quatro séculos ${ }^{6}$.

O Reitor do Seminário Arquidiocesano, instalado no antigo Colégio dos Jesuítas de Olinda, residia em uma casa junto a Sé daquela cidade. Na igreja da Sé começou esse padre, a remover o reboco, o qual estava caindo de uma das colunas da igreja. Descobriu, na oportunidade, que ela era em pedra calcária e, desde então, foram sendo realizadas várias pesquisas sobre o que, nesse material, existia edificado na igreja. Muitas perfilaturas e arcadas das capelas laterais, além de vários outros elementos em cantaria foram então descobertos. Existia sob a camada de estuques das intervenções, dos anos de 1911 e 1936, uma igreja, bem mais antiga e com tais cantarias. Igualmente os achados também na fachada principal levaram a uma dissertação

ruína um bem cultural imóvel e edificado, não parece senão um procedimento muito valorizado pelo Romantismo e em termos mais recuado da história presente, no gosto pelos pintores pós Renascimento e na arte dos jardins no século XIX.

${ }^{5} \mathrm{Na}$ França pode-se identificar com mais intensidade as ações de restauração dos bens culturais destruídos pela Revolução de 1789. Com Napoleão III organizou-se um Departamento destinado, no governo, para tal finalidade. Deste, de uma maneira geral, emanaram várias, algumas discutíveis, teorias sobre o ato do Restaurar, vindas também da Itália, para o restante da Europa.

${ }^{6}$ Tal resultado deveu-se aos procedimentos adotados pelo 1을 Distrito do Serviço do Patrimônio Histórico e Artístico Nacional, dirigido pelo engenheiro Ayrton de Almeida Carvalho, este profissional muito cuidadoso no trato da recuperação dos bens culturais de Pernambuco. Teve este chefe de Distrito total apoio, em suas decisões, da Presidência do DPHAN, então com o Advogado Rodrigo Mello Franco de Andrade. A medida resultante estava muito longe daquelas defendidas, em igual época, na Europa, essencialmente em Portugal. 
de mestrado na Universidade Federal de Pernambuco e esta fundamentou a proposta de restituição da igreja a sua condição atual'.

A primeira notícia, em depoimento sobre a matriz de Olinda, depois Sé, data de 1584, sendo uma descrição do estado da igreja, então sendo edificada: "a nova igreja matriz encontra-se a em andamento a construção de três naves, com muitas capelas ao redor, e acabada ficará uma boa obra" ${ }^{8}$. O emprego de um modelo de igreja com três naves, separadas por arcadas suportadas por colunas, com capelas ao redor, veio de Portugal, existindo naquele país, muitos exemplos desse tipo. A igreja, naquele ano, deveria apresentar as características da arquitetura do Maneirismo, onde o domínio da leitura interior deixava bem patente a linguagem arquitetônica, decorrente do uso dos Tratados, onde a ornamentação restringia-se aos retábulos, situados nos fundos das capelas, uma linguagem arquitetônica comum ao modelo ora adotado em Olinda.

Com a ocupação de Pernambuco pela gente dos Países-Baixos, de 1630 a 1654, Olinda foi incendiada (1631) e a igreja matriz ficou bem destruída. Assim ela é vista em várias pinturas do artista Franz Post, holandês vindo com o alemão João Maurício de Nassau, (1637-1644), para governar a conquista da Companhia das Índias Ocidentais no Brasil. Depois de 1654 a igreja é reconstruída mantendo o modelo anterior e completando a construção das seis capelas ao redor. No correr do tempo, entre 1654 e 1911, a igreja foi enriquecida, por sobre aquela base Maneirista, com altares e forros entalhados e ainda azulejos nas laterais da nave. Em 1911 sofreu a primeira intervenção e perdeu suas pinturas e demais ornamentos, inclusive os altares das capelas laterais que foram demolidas. Um ecletismo desconcertado restou depois de 1936, quando a igreja veio a ser alvo de nova intervenção, a ponto de um depoimento de época dizer: o melhor é por uma placa na frente da igreja e informar: "aqui existiu a Sé de Olinda"

Com tal aspecto chegou a igreja até aos anos setenta do século passado, no qual foi escolhida para ser reparada do estado em que se encontrava. A proposta foi mais além. Com o texto dos achados naquelas pesquisas e a leitura da igreja na dissertação referida, onde estava delineada em seu aspecto Maneirista, foi realizada uma proposta de restauração, a ser materializada pelo Programa de Restauração das Cidades Históricas do Nordeste. Uma escolha do Programa que levou a mais pesquisas, quando da execução das obras.

Nada restando dos ornatos e dos antigos altares, o partido adotado foi conduzir a proposta final, segundo a documentação identificada nas pesquisas arqueológicas, para uma igreja, onde sua forma (design) fosse a mais aproximada possível daquele Maneirismo. As perfilaturas e a simplicidade do desenho em muito ajudou e fundamentou os resultados. Era assim, uma reconstituição e não uma restauração a ser de acordo com o visto anteriormente. Uma restituição dos valores arquitetônicos identificados nos perfis bem elaborados daquela igreja

\footnotetext{
${ }^{7}$ A decisão em recuperar o estado no qual se encontrava o monumento foi tomada pelo Programa de Restauração das Cidades Históricas do Nordeste. Escolha foi dos vários dos gestores culturais presentes na instalação do referido programa.

8 COSTA, Lúcio. A arquitetura dos Jesuítas no Brasil. ARS (São Paulo), vol.8, n.16, São Paulo, 2010.
} 
quinhentista. Mais importante dos momentos do edifício e visíveis nos achados. Não aconteceu, conforme se disse na época invenções e sim determinações de espaço e tratamento à luz do que foi encontrado nas pesquisas. Todas as definições finais estavam de acordo coma filosofia da restauração adotada pelo órgão oficial (Iphan), conforme documentação existente na Fundação do Patrimônio Histórico e Artístico de Pernambuco Fundarpe. A linha condutora do projeto teve como fundamento o design proposto, conforme descrito naquela informação, de teor Maneirista, e realizado à luz dos elementos dessa possível proposta, evidentes nos achados arqueológicos ${ }^{9}$.

O considerado, até então, como ação de restauração em um bem material edificado, quando tem por objetivo não uma parte conhecida da edificação, mas uma reparação de maior porte e com determinada finalidade, nem sempre pode ter como referência o princípio, início/fim, determinado e conhecido naqueles exemplos de obras de pintura e da escultura. Em situações como a da arquitetura, onde o correr do tempo Ihe altera a forma, tem-se como indagação principal a contida em um livro de Kelvin Linch: de que tempo é este lugar? ${ }^{10}$

Diante do visto, aquele princípio aplicável aos bens culturais móveis, considerados nos exemplos, nos parece falso, enquanto seu emprego para a arquitetura. $O$ resultado alcançado segundo ele seria talvez impossível. Sendo tal assertiva verdadeira, seria falso empregar o termo restauração, segundo os parâmetros dos bens móveis para a arquitetura. O que levaria a construção de uma teoria da restauração, ou reconstituição, apropriada ao bem material imóvel e edificado.

O fundamental da arquitetura reside no espaço interior... O espaço da arquitetura é o seccionamento do espaço geral...(Evaldo Coutinho - O espaço na Arquitetura) ${ }^{11}$

Espaço interior cuja leitura, sua percepção, pode ser diferente para cada um, segundo tempo e lugar, duas pelo menos condições essenciais de sua existência ${ }^{12}$. Por outro lado, um projeto, é considerado, enquanto concepção, atualmente como mesmo significado de design, cuja materialidade reveste-se de situações estéticas, então relacionadas com cada ator ou agente responsável pelo ato da criação. Criação, no caso da arquitetura, sujeita a outros atores, além daquele que the deu a forma inicial, segundo aquela condição tempo e espaço, onde o uso, o caráter utilitário do edificado, pode lhe alterar tal forma como foi visto. Deste modo, uma obra edificada dificilmente poderá ser entendida, senão segundo o seu espaço interno, e não à luz

\footnotetext{
${ }^{9}$ A reconstituição da fachada fundamentou-se, conforme documentação do arquivo da Fundarpe, em vestígios encontrados sob uma parede de alvenaria de tijolos que suportava os ornatos em massa realizados pelas duas intervenções, de 1911 e 1936. Quanto à recomposição das capelas laterais, esta enquanto procedimento foi tomado, antes de 1972, na Sala do Capítulo do Convento dos Franciscanos em João Pessoa, na Paraíba, na Igreja dos Santos Cosme e Damião, em Igarassu e noutras obras do Sphan. Encontrava a medida amparo em teorias européias em caso semelhantes.

${ }^{10}$ A restauração, assim parece, não pode ser direcionada, neste termos a um tempo determinado, razão a qual nos leva àquela condição de busca de outros parâmetros para situações iguais às dos exemplos narrados.

${ }^{11}$ COUTINHO, Evaldo. O espaço da arquitetura. Recife: Universidade Federal de Pernambuco, 1970.

${ }^{12}$ Coutinho, ao considerar o caráter filosófico da percepção da arquitetura, utiliza a expressão espaço interno, enquanto contendo a relação deste com quem o percebe e no estado no qual o observador o vê. O termo, no caso se aplica, mas chama-se espaço interior, aquele vazio da arquitetura onde possa em igual momento ou depois, ocorrer um suporte para a ornamentação além da tectônica propriamente dita.
} 
de princípios que regem a autonomia das demais artes, por exemplos, a pintura e a escultura. Não se pode analisar a arquitetura com os parâmetros que regem a autonomia da pintura e da escultura. O sentido de unidade, completude, não estaria absolutamente seguro para se aplicar à arquitetura, uma vez que ela tem, na sua existência, a presença de um espaço subjetivo, que pode se alterar, ou não, por conta da condição de seu uso e suapercepção.

No entanto, assim acredita-se, por mais que se altere a obra edificada da arquitetura, resiste nela a condição espacial que a criou, apesar das intervenções sofridas. Um design, que a identificou, este contido no seu cerne, uma vez que atrelado aos parâmetros que a fizeram projeto e construção. Acredita-se que, por maior que seja a intervenção, o princípio espacial gerador da forma primeira, talvez ainda possa ser identificado ao longo do tempo.

Arquitetura é antes de mais nada construção, mas, construção concebida com o propósito primordial de ordenar e organizar o espaço para determinada finalidade e visando a determinada intenção (COSTA, 2010).

O que se verifica, nos exemplos de restauração ou reconstituição antes apresentados, deixa patente que o espaço interior, seu design, nas duas situações, pode ter determinado a condução dos resultados. Senão veja: no caso do interior da igreja franciscana, os diversos momentos do espaço interior da nave e capela-mor se integraram numa leitura atemporal. No caso da Sé de Olinda, o design inicial, alvo de intervenções ornamentais posteriores, que the alteraram com novos elementos ornamentais a leitura do espaço suporte, este quando desprovido de tais intervenções, mostrou-se em toda a sua plenitude à luz do Maneirismo que Ihe marcou a arquitetura interior e exterior dos seus primeiros dias. Não ocorreu a busca da forma prístina, segundo Viollet-Le-Duc ${ }^{13}$, mas o desaparecimento das ornamentações somadas ao espaço edificado e criado no século XVI, valorizou sensivelmente a leitura do seu espaço interno. Lembrando, na oportunidade o que acontecia com a arquitetura romana, onde o espaço suporte moldado (estrutural) era vestido com uma ornamentação, embora isto em momento quase que imediato e participando da concepção, design, desejado pelos criadores. No caso da arquitetura da igreja franciscana, o espaço suporte está presente sob as talhas e os momentos diferentes da leitura da nave capela-mor. Tal situação aconteceu no Barroco, quando interiores Maneiristas foram enriquecidos por exuberantes ornamentações da talha em madeira ou pedra. Não sendo este o caso da arquitetura criada no período artístico considerado.

O espaço suporte que ora se considera é aquele determinado pelo vazio da arquitetura, a tectônica, que pode ser constituído ou não dos elementos de perfilaturas e anterior, no caso do Barroco no Brasil, a toda a ornamentação em talha de forros e retábulos. Não que estes elementos decorativos não sejam em determinado tempo integrados à arquitetura de tal espaço suporte, mas este é o direcionador de tudo quanto à concepção do design. É o risco inicial e determinante gerador de tudo. No Recife, a chamada Capela Dourada é uma igreja

\footnotetext{
${ }^{13}$ Um desvio natural, por conta dos Estudos Históricos, dominantes no século XIX, do grande teórico da restauração Viollet Le Duc, o qual foi além da recuperação das edificações, buscando a forma da arquitetura enquanto resultado desejado e não o que efetivamente foi edificado, caso da grande intervenção na cidade de Carcassone, na França.
} 
que se incluiu em outra que está subjacente no conjunto final. $O$ entalhador, inclusive deixou, ao entalhar a madeira pela sua parte interior, colada aos perfis de cantaria, isto bem claro.

$\mathrm{Na}$ arquitetura para fins da religião cristã, no Brasil, pela própria natureza das obras de enriquecimento das diversas gerações, no convívio com a edificação, o design inicial vai sendo alvo de intervenções, mudando tal ação a leitura interna dos ambientes, mas não retirando deles, na maioria dos casos, o seu design inicial, ou matriz mais antiga, aquele espaço suporte.

Resta uma indagação final: não seria importante a busca por tal espaço suporte, enquanto uma das diretrizes para a adoção dos atos de restauração ou reconstituição de um bem cultural edificado, quando este sofreu intervenções que levam à necessidade de obras de reparo de sua arquitetura?

Por outro lado, tem-se que entender bem o que se considera restauração, ou seja, uma ação do restaurar danos de uma parte da arquitetura existente e não desaparecida e reconstituir, que recompõe e poderia completar trechos destruídos e desaparecidos, estes indispensáveis para a leitura do design da edificação.

Simples reflexões sobre um tema tão complexo. 